\title{
High prevalence of low plasma thiamine concentration in diabetes linked to a marker of vascular disease
}

\author{
P. J. Thornalley $•$ R. Babaei-Jadidi $\cdot$ H. Al Ali $•$ \\ N. Rabbani • A. Antonysunil • J. Larkin • A. Ahmed • \\ G. Rayman • C. W. Bodmer
}

Received: 23 February 2007 / Accepted: 22 June 2007 / Published online: 4 August 2007

(C) Springer-Verlag 2007

\begin{abstract}
Aims/hypothesis To assess thiamine status by analysis of plasma, erythrocytes and urine in type 1 and type 2 diabetic patients and links to markers of vascular dysfunction. Methods Diabetic patients (26 type 1 and 48 type 2) with and without microalbuminuria and 20 normal healthy control volunteers were recruited. Erythrocyte activity of transketolase, the concentrations of thiamine and related phosphorylated metabolites in plasma, erythrocytes and urine, and markers of metabolic control and vascular dysfunction were determined.

Results Plasma thiamine concentration was decreased $76 \%$ in type 1 diabetic patients and $75 \%$ in type 2 diabetic patients: normal volunteers 64.1 (95\% CI 58.5-69.7) nmol/1, type 1 diabetes $15.3(95 \%$ CI $11.5-19.1) \mathrm{nmol} / 1, p<$
\end{abstract}

P. J. Thornalley $\cdot$ R. Babaei-Jadidi $\cdot H$. Al Ali $\cdot$ N. Rabbani A. Antonysunil $\cdot$ J. Larkin

Department of Biological Sciences, University of Essex,

Colchester, Essex, UK

P. J. Thornalley $(\bowtie) \cdot N$. Rabbani $\cdot$ A. Antonysunil $\cdot$ J. Larkin Clinical Sciences Research Institute, Warwick Medical School, University of Warwick, University Hospital,

Clifford Bridge Road,

Coventry CV2 2DX, UK

e-mail: P.J.Thornalley@warwick.ac.uk

A. Ahmed $\cdot$ C. W. Bodmer

Department of Diabetes and Endocrinology,

Colchester General Hospital,

Colchester, Essex, UK

G. Rayman

Ipswich Diabetic Foot Unit and Diabetes Centre,

Ipswich Hospital NHS Trust,

Ipswich, UK
0.001, and type 2 diabetes 16.3 (95\% CI 13.0-9.6) nmol/1, $p<0.001$. Renal clearance of thiamine was increased 24fold in type 1 diabetic patients and 16-fold in type 2 diabetic patients. Plasma thiamine concentration correlated negatively with renal clearance of thiamine $(r=-0.531, p<$ $0.001)$ and fractional excretion of thiamine $(r=-0.616, p<$ $0.001)$. Erythrocyte transketolase activity correlated negatively with urinary albumin excretion $(r=-0.232, p<0.05)$. Thiamine transporter protein contents of erythrocyte membranes of type 1 and type 2 diabetic patients were increased. Plasma thiamine concentration and urinary excretion of thiamine correlated negatively with soluble vascular adhesion molecule-1 ( $r=-0.246, p<0.05$, and $-0.311, p<0.01$, respectively).

Conclusions/interpretation Low plasma thiamine concentration is prevalent in patients with type 1 and type 2 diabetes, associated with increased thiamine clearance. The conventional assessment of thiamine status was masked by increased thiamine transporter content of erythrocytes.

Keywords Adhesion molecules - Microalbuminuria . Thiamine · Type 1 diabetes Type 2 diabetes

\begin{tabular}{ll}
\multicolumn{2}{l}{ Abbreviations } \\
$\mathrm{ARB}$ & angiotensin receptor blocker \\
$\mathrm{Cl}_{\text {Thiamine }}$ & renal clearance of thiamine \\
$\mathrm{FE}_{\text {Thiamine }}$ & $\begin{array}{l}\text { fractional excretion of thiamine } \\
\text { MNL }\end{array}$ \\
mononuclear leucocyte \\
RFC-1 & reduced folate carrier-1 \\
sVCAM-1 & soluble vascular adhesion molecule-1 \\
THTR-1 & thiamine transporter-1 \\
THTR-2 & thiamine transporter-2 \\
TK & transketolase \\
TMP & thiamine monophosphate \\
TPP & thiamine pyrophosphate
\end{tabular}




\section{Introduction}

Diabetes is increasing in incidence in the UK and elsewhere to epidemic proportions. The major health concerns of diabetes are achieving good control of blood glucose, BP and lipids to suppress the development of associated vascular complications - microvascular complications (nephropathy, retinopathy and peripheral neuropathy) and macrovascular complications (cardiovascular disease and stroke) $[1,2]$. This is not always achievable because of limitations of current drug therapy, patient compliance and other factors linked to the development of vascular complications [3]. Secondarily to the global epidemic of diabetes, therefore, is a global burden of vascular complications [4]. The significant residual risk of development of microvascular and macrovascular complications in prospective clinical trials where best efforts have been made to optimise glycaemic control $[5,6]$, and the failure of major genetic susceptibility factors for diabetic complications to emerge from intensive studies [7] (although some may be found with further study $[8,9]$ ), encourage the search for other metabolic and nutritional factors that may predispose to the development of vascular complications in diabetes.

Vascular complications develop progressively from 540 years after the onset of diabetes, although they may appear earlier in type 2 diabetes when associated with a period of undiagnosed diabetes and impaired glucose tolerance. A strategy to counter multiple pathways of biochemical dysfunction linked to the development of vascular complications emerged from recent advances in understanding of the cell biology of diabetic complications: high-dose therapy with thiamine and related derivatives such as benfotiamine. High-dose thiamine therapy prevented the development of microvascular complications in experimental diabetes without improvement of metabolic control, as reviewed in [10]. Experimental diabetes was also associated with tissuespecific thiamine deficiency characterised by a marked decrease of plasma thiamine concentration and decreased activity of the thiamine-dependent enzyme of transketolase (TK) and decreased levels of TK protein in renal glomeruli linked to a profound increase in renal clearance of thiamine $\left(\mathrm{Cl}_{\text {Thiamine }}\right)$ [11]. Thiamine deficiency was not detected by the conventional indicator of thiamine status, the erythrocyte 'thiamine effect' (the percentage unsaturation of TK with thiamine pyrophosphate [TPP] cofactor) [12]. The prevalence of similar low plasma thiamine concentrations and impaired renal handling of thiamine in clinical diabetes has not been addressed previously.

In this study, we sought to establish whether there is a disturbance of thiamine homeostasis prevalent in type 1 and type 2 diabetic patients in the UK and if this is linked to incipient nephropathy and markers of vascular dysfunction and early stage renal dysfunction.

\section{Methods}

Patients and normal healthy volunteers Diabetic patients were recruited from patients attending the Diabetes Clinic at Colchester General Hospital, and normal healthy control volunteers from partners and friends of the patients and investigators. Inclusion criteria were: diabetic patients with normoalbuminuria (AER $<30 \mathrm{mg} / 24 \mathrm{~h}$ ) and microalbuminuria (AER 30-300 mg/24 h); matched for age and sex (1865 years); diabetes duration of $\geq 5$ years; $\mathrm{HbA}_{1 \mathrm{c}}<10 \%$; and BMI $19-40 \mathrm{~kg} / \mathrm{m}^{2}$. Exclusion criteria were: patients with end-stage renal disease; severe excess alcohol consumption ( $>50 \mathrm{U}$ per week; $1 \mathrm{U}$ is $8 \mathrm{~g}$ alcohol); significant comorbidities; known allergy or intolerance to thiamine; use of thiamine supplements or goldenseal (Hydrastis canadensis, a multipurpose herbal remedy); participating in an intervention study within 30 days; recipients of renal and/or pancreatic transplants; and women who were pregnant or breastfeeding or of child-bearing potential not using adequate contraceptive precautions. Twenty-four hour urine collections and blood samples (fasting) were taken with informed consent of the patients and volunteers. Plasma, erythrocyte and mononuclear leucocyte (MNL) fractions were prepared immediately and stored at $-80^{\circ} \mathrm{C}$ until analysis. Ethical approval for the study was given by the local ethics committee (North and Mid-Essex Local Research Ethics Committee).

Assay of thiamine and phosphorylated metabolites Thiamine status was assessed by measurement of thiamine, thiamine monophosphate (TMP) and TPP, determined by HPLC with fluorimetric detection (pre-column derivatisation to thiachromes) [13]. The retention times, limits of detection, interbatch $\mathrm{CV}$ values and recoveries for these metabolites were: thiamine $13.1 \mathrm{~min}, 36 \mathrm{fmol}, 1.1$ and 97\%; TMP $6.0 \mathrm{~min}, 52 \mathrm{fmol}, 2.1$ and 92\%; and ТРP $4.5 \mathrm{~min}, 51 \mathrm{fmol}, 2.9$ and $94 \%$. There was no interference from glucose in the assay and validations were not significantly different in analysis of samples from normal healthy volunteers and diabetic patients. Sample storage studies indicated that analyte content was stable for plasma, erythrocytes and urine stored at $-80^{\circ} \mathrm{C}$ for at least 6 weeks and storage of plasma, erythrocyte haemolysate and urine and related de-proteinised extracts for $8 \mathrm{~h}$. Stock solutions of thiamine, TMP and TPP were calibrated by spectrophotometry assuming molar extinction coefficients of $\varepsilon_{233}=$ $14.2, \varepsilon_{247}=15.3$ and $\varepsilon_{247}=13.0(\mathrm{mmol} / 1)^{-1} \mathrm{~cm}^{-1}$, respectively [14]. Shewhart analysis assessing the stability of analyte estimates in samples every day over a period of ten consecutive days indicated the analysis had acceptable quality control (all estimates within mean $\pm 2 \mathrm{SD}$ ) [15]. The concentration of thiamine metabolites was determined in plasma, erythrocytes and urine; $\mathrm{Cl}_{\text {Thiamine }}$ and fractional excretion of thiamine $\left(\mathrm{FE}_{\text {Thiamine }}\right)$ were deduced. 
Other biochemical measurements Erythrocyte TK activity and percentage unsaturation with TPP (thiamine effect) were determined. Erythrocyte membrane content of thiamine transporter-1 (THTR-1) [16] and reduced folate carrier-1 (RFC-1), a transporter of TMP [17], were determined by SDS-PAGE electrophoresis and western blotting, normalising band intensities to $\beta$-actin and preparing erythrocyte membrane protein extracts using the optimised procedure described in [18], and commercial antibodies to THTR-1 and RFC-1 (Alpha Diagnostics, San Antonio, CA, USA).

Markers of metabolic control were determined: plasma glucose, $\mathrm{HbA}_{1 \mathrm{c}}$, total cholesterol, HDL-cholesterol, triacylglycerol, systolic and diastolic BP and GFR assessed by Cockcroft-Gault-corrected creatinine clearance. Markers of vascular and metabolic dysfunction (plasma plasminogen activator inhibitor-1; von Willebrand factor and soluble vascular adhesion molecule-1 [sVCAM-1]; and MNL protein kinase C) were determined by commercial ELISAs (Technoclone, Dorking, UK; R\&D Systems, Abingdon, UK; and Stressgen, Ann Arbor, MI, USA, respectively).

Statistical analysis The significance of differences between mean and median analyte concentrations was determined using Student's $t$ test and the Mann-Whitney $U$ test, respectively, and correlation analysis was performed by calculating Spearman's $\rho$ statistic, as indicated in the text. Data presented are mean $\pm \mathrm{SD}$ or median (minimummaximum).

\section{Results}

Patient characteristics The characteristics of type 1 and type 2 diabetic patients and normal healthy control volunteers recruited for this study are given in Table 1 . The diabetic patients had moderate glycaemic control; mean $\mathrm{HbA}_{1 \mathrm{c}}$ was $8.6-8.7 \%$. GFR was within the normal range, indicative of normal renal function for creatinine clearance. Fifty diabetic patients (17 type 1 and 33 type 2) had urinary albumin excretion within the normal range (median 11.5, 2.3-29.1 mg/24 h) and 24 had urinary albumin excretion characteristic of microalbuminuria and incipient nephropathy (median 46.1, 30.6-297.3 mg/24 h). Diabetic patients with and without microalbuminuria were of similar age ( $60 \pm 14$ vs $56 \pm 15$ years), duration of diabetes $(17 \pm 11$ vs $16 \pm 12$ years $)$ and $\mathrm{HbA}_{1 \mathrm{c}}(8.9 \pm 1.9$ vs $8.5 \pm$ $1.5 \%)$. Nine type 1 diabetic patients and 33 type 2 diabetic patients were receiving therapy with ACE inhibitors or angiotensin receptor blockers (ARBs).

Thiamine status of patients with type 1 and type 2 diabetes Surveying the thiamine status in the study patients and normal volunteer groups, we found the plasma concentration of thiamine was decreased $76 \%$ and $75 \%$ in type 1 and type 2 diabetic patients, respectively. The plasma concentration of thiamine (mean $\pm \mathrm{SD}$ ) was: normal volunteers $64.1 \pm 12.0 \mathrm{nmol} / \mathrm{l}$, type 1 diabetes $15.3 \pm 9.6 \mathrm{nmol} / 1$ and type 2 diabetes $16.3 \pm 11.5 \mathrm{nmol} / 1, p<0.001$ (Student's $t$ test) (Fig. 1a). There was no significant difference between plasma thiamine concentration of type 1 and type 2 diabetic patients or between diabetic patients with and without microalbuminuria $(14.4 \pm 8.9$ vs $16.7 \pm 11.6 \mathrm{nmol} / \mathrm{l}$, $p>0.05$ ). The urinary excretion of thiamine was increased fourfold and threefold in type 1 and type 2 diabetic patients with respect to normal volunteers. The urinary excretion of thiamine (median, minimum-maximum) was: normal volunteers $0.31(0.23-2.45) \mu \mathrm{mol} / 24 \mathrm{~h}$; type 1 diabetes 1.36 (0.39-7.65) $\mu \mathrm{mol} / 24 \mathrm{~h}$; and type 2 diabetes $1.04(0.08$ 6.85) $\mu \mathrm{mol} / 24 \mathrm{~h}, p<0.001$ (Mann-Whitney $U$ test). The urinary excretion of thiamine was higher in type 1 than in type 2 diabetic patients $(p<0.05)$ but was not significantly different in diabetic patients with and without microalbuminuria $[1.10(0.08-7.65)$ vs $1.23(0.33-6.85) \mu \mathrm{mol} /$ $24 \mathrm{~h}, p>0.05$ ]. $\mathrm{Cl}_{\text {Thiamine }}$ was increased 24-fold in type 1 diabetic patients and 16-fold in type 2 diabetic patients. $\mathrm{Cl}_{\text {Thiamine }}$ (median, minimum-maximum) was: normal volunteers $3.7(2.6-26.2) \mathrm{ml} / \mathrm{min}$; type 1 diabetes 86.5 (12.8-228.4) $\mathrm{ml} / \mathrm{min}$; and type 2 diabetes $59.8(1.4-256.6)$

Table 1 Characteristics of normal control volunteers and diabetic patients recruited for this study

\begin{tabular}{|c|c|c|c|c|c|c|c|c|c|c|c|}
\hline $\begin{array}{l}\text { Participant } \\
\text { type }\end{array}$ & $n$ & $\begin{array}{l}\text { Sex } \\
M / F\end{array}$ & $\begin{array}{l}\text { Age } \\
\text { (years) }\end{array}$ & $\begin{array}{l}\text { Duration } \\
\text { of diabetes } \\
\text { (years) }\end{array}$ & $\begin{array}{l}\text { BMI } \\
\left(\mathrm{kg} / \mathrm{m}^{2}\right)\end{array}$ & $\begin{array}{l}\text { GFR } \\
(\mathrm{ml} / \mathrm{min})\end{array}$ & $\begin{array}{l}\text { Fasting plasma } \\
\text { glucose }(\mathrm{mmol} / \mathrm{l})\end{array}$ & $\begin{array}{l}\mathrm{HbA}_{1 \mathrm{c}} \\
(\%)\end{array}$ & $\begin{array}{l}\text { Systolic BP } \\
(\mathrm{mmHg})\end{array}$ & $\begin{array}{l}\text { Diastolic } \\
\mathrm{BP}(\mathrm{mmHg})\end{array}$ & $\begin{array}{l}\text { ACE inhibitor/ } \\
\text { ARB therapy }\end{array}$ \\
\hline Control volunteers & 20 & $10 / 10$ & $53 \pm 10$ & - & $27 \pm 4$ & $89 \pm 18$ & $5.6 \pm 0.8$ & $5.0 \pm 0.2$ & ND & ND & - \\
\hline Type 1 diabetes & 26 & $10 / 16$ & $48 \pm 15$ & $22.1 \pm 13.3$ & $28 \pm 5$ & $93 \pm 28$ & $9.2 \pm 1.7^{*}$ & $8.7 \pm 1.2 *$ & $131 \pm 21$ & $73 \pm 11$ & 9 \\
\hline Type 2 diabetes & 48 & $29 / 19$ & $62 \pm 12$ & $13.0 \pm 8.9 * *$ & $31 \pm 6$ & $92 \pm 30$ & $9.1 \pm 2.2 *$ & $8.6 \pm 1.8^{*}$ & $141 \pm 22$ & $77 \pm 9$ & 33 \\
\hline
\end{tabular}

Data are mean \pm SD.

$N D$ Not determined

$* p<0.001$ with regard to normal volunteers

$* * p<0.01$ with regard to type 1 diabetes (Mann-Whitney $U$ test) 
a

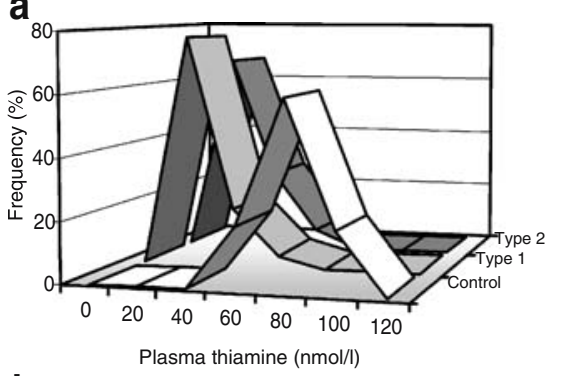

b

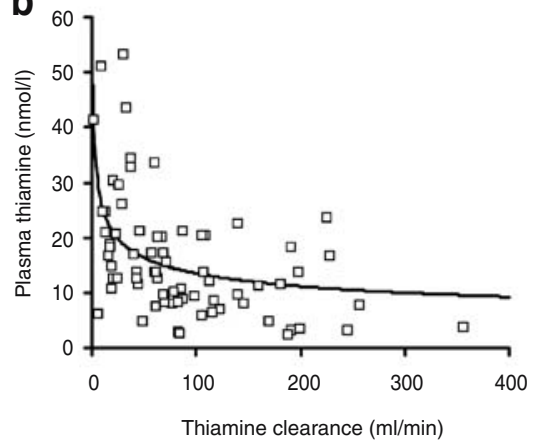

C

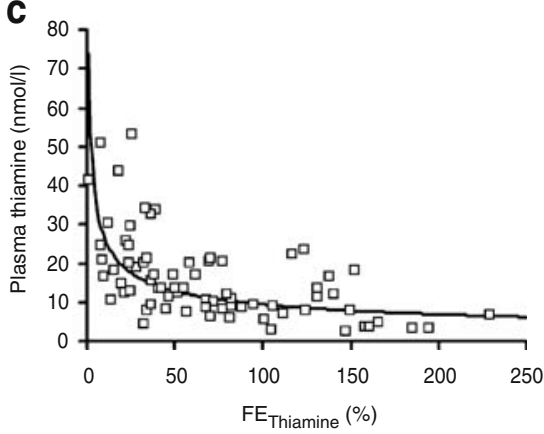

Fig. 1 Thiamine status of diabetic patients and link to sVCAM-1. a Frequency ribbon graph of plasma thiamine concentration. b Inverse relationship between plasma thiamine concentration and thiamine clearance. Nonlinear regression equation: [Thiamine $]_{\text {Plasma }}=47.7 \times$ $\mathrm{Cl}_{\text {Thiamine }}-0.274, p<0.001$. c Inverse relationship between plasma thiamine concentration and $\mathrm{FE}_{\text {Thiamine }}$ Nonlinear regression equation: $[\text { Thiamine }]_{\text {Plasma }}=74.0 \times \mathrm{FE}_{\text {Thiamine }}^{-0.448}, p<0.001$

$\mathrm{ml} / \mathrm{min}, p<0.001$ (Mann-Whitney $U$ test). There was no significant difference in $\mathrm{Cl}_{\text {Thiamine }}$ between diabetic patients with and without microalbuminuria (72.9 [1.4-355.7] vs 66.3 [5.8-245.3] ml/min). $\mathrm{FE}_{\text {Thiamine }}$ was increased 25-fold in type 1 diabetic patients and 15-fold in type 2 diabetic patients. $\mathrm{FE}_{\text {Thiamine }}$ (median, minimum-maximum) was: normal volunteers $2.8 \%(1.4-17.2 \%)$; type 1 diabetes $71.2 \%(7.6-165.9 \%)$; and type 2 diabetes $41.6 \%$ (1.1$228.9 \%$ ), $p<0.001$ (Mann-Whitney $U$ test). There was no significant difference in $\mathrm{FE}_{\text {Thiamine }}$ between diabetic patients with and without microalbuminuria $(57.7 \%$ [8.0 $228.9 \%$ ] vs $43.4 \%$ [1.1-165.9\%]). Plasma thiamine concentration correlated negatively with $\mathrm{Cl}_{\text {Thiamine }}(r=-0.531$, $p<0.001$; Spearman) and $\mathrm{FE}_{\text {Thiamine }}(r=-0.616, p<0.001$; Spearman) (Fig. 1b,c). There was no significant difference in these thiamine-related variables between diabetic patients with and without ACE or ARB therapy.

Thiamine deficiency is assessed conventionally by assay of TK activity of erythrocytes [12]. Erythrocyte activity of TK was not changed significantly in diabetic patients, with regard to normal volunteers. TK activity was: normal volunteers $1.09 \pm 0.06 \mathrm{mU} / \mathrm{mg} \mathrm{Hb}$; type 1 diabetes $1.18 \pm$ $0.25 \mathrm{mU} / \mathrm{mg} \mathrm{Hb}$; and type 2 diabetes $1.01 \pm 0.17 \mathrm{mU} / \mathrm{mg}$ $\mathrm{Hb}$. Erythrocyte activity of TK was not significantly different in diabetic patients with and without microalbuminuria $(1.03 \pm 0.24$ vs $1.08 \pm 0.21 \mathrm{mU} / \mathrm{mg} \mathrm{Hb})$, although it correlated negatively with urinary albumin excretion ( $r=-0.232, p<0.05$; Spearman). All patients were not thiamine deficient by the definition of the 'thiamine effect'; they had a thiamine effect of $<15 \%$. The concentration of thiamine in erythrocytes was not changed significantly in type 1 and type 2 diabetic patients, with respect to normal volunteers. The concentration of thiamine in erythrocytes (mean $\pm \mathrm{SD}$ ) was: normal volunteers $0.318 \pm$ $0.028 \mathrm{pmol} / \mathrm{mg} \mathrm{Hb}$; type 1 diabetes $0.345 \pm 0.025 \mathrm{pmol} / \mathrm{mg}$ $\mathrm{Hb}$; and type 2 diabetes $0.328 \pm 0.137 \mathrm{pmol} / \mathrm{mg} \mathrm{Hb}$.

Masking of the clinical thiamine deficiency in erythrocytes by increased levels of thiamine transporter proteins We sought evidence to understand how erythrocytes of diabetic patients maintained a normal concentration of thiamine whilst the plasma concentration of thiamine was severely decreased. The transport of thiamine and TMP from plasma to the interior of erythrocytes is mediated by the transporters THTR-1 and RFC-1, respectively (Fig. 2a). Western blotting of erythrocyte membrane proteins from diabetic patients showed increased contents of these transporters compared with membrane-associated housekeeping protein $\beta$-actin (Fig. 2b). Thiamine transporter: $\beta$-actin blot intensity ratios (median, minimum-maximum) were: normal volunteers $(n=10)$, THTR-1 $0.69(0.12-1.43)$ and RFC-1 $0.042(0.012-0.093)$; type 1 diabetes $(n=12)$, THTR-1 $1.06(0.64-2.02)(+54 \%, p<0.05)$ and RFC-1 $0.146(0.021-0.902)(+248 \%, p<0.01)$; and type 2 diabetes $(n=12)$, THTR-1 $1.20(0.62-2.39)(+74 \%, p<0.01)$ and RFC-1 $0.206(0.038-1.382) \quad(+390 \%, p<0.001) \quad(M a n n-$ Whitney $U$ tests).

Low plasma thiamine concentration and markers of metabolic control and vascular dysfunction We screened markers of metabolic control and vascular dysfunction in diabetes for linkage to the low plasma thiamine concentration in diabetes. The only significant correlations were of plasma thiamine concentration with plasma SVCAM-1 $(r=$ $-0.246, p<0.05$; Spearman) (Fig. 3a) and urinary excretion of thiamine with plasma sVCAM-1 $(r=-0.311, p<0.01)$ (Fig. 3b). 


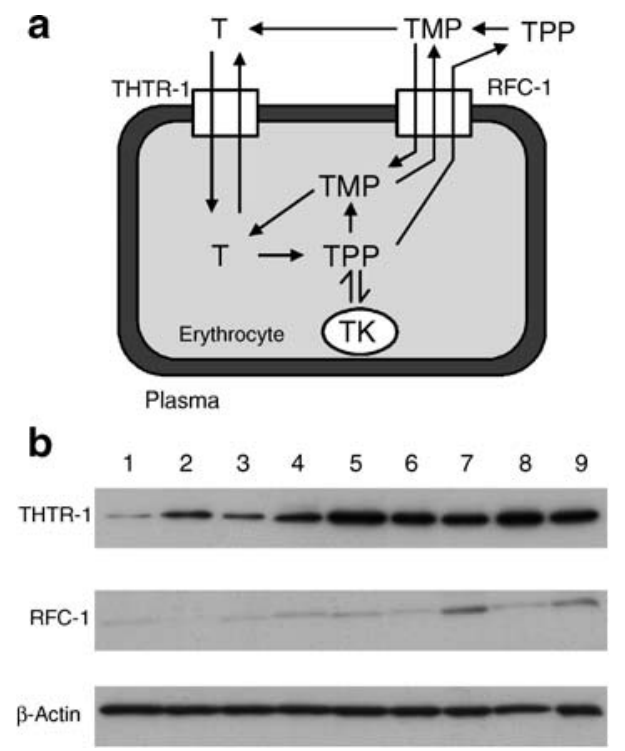

Fig. 2 a Schematic diagram of thiamine membrane transport and metabolism in erythrocytes. b Representative Western blot of THTR-1, RFC-1 and housekeeping protein $\beta$-actin of erythrocyte membranes. Lanes 1-3, normal volunteers; lanes 4-6, type 1 diabetic patients; and lanes $7-9$, type 2 diabetic patients. $T$, Thiamine

\section{Discussion}

In this study we found clinical diabetes was associated with a marked deficiency of thiamine in blood plasma linked to increased $\mathrm{Cl}_{\text {Thiamine }}$ and $\mathrm{FE}_{\text {Thiamine. The low plasma }}$ thiamine concentration in diabetes was linked inversely to plasma sVCAM-1.

The strengths of this study were the use of a validated assay for thiamine and phosphorylated metabolites, a comprehensive assessment of thiamine-related variables (including thiamine transporter content of erythrocyte membranes, urinary excretion, $\mathrm{Cl}_{\text {Thiamine }}$ and $\mathrm{FE}_{\text {Thiamine }}$ ) and investigation of the association of thiamine-related variables with markers of metabolic and vascular dysfunction. The decreased plasma thiamine concentration in clinical diabetes was probably not due to a deficiency of dietary input of thiamine. The urinary excretion of thiamine of diabetic patients and normal healthy volunteers was within the normal range $(>0.20 \mu \mathrm{mol} / 24 \mathrm{~h})$ [19], except for one type 2 diabetic patient with a urinary thiamine excretion of $0.08 \mu \mathrm{mol} / 24 \mathrm{~h}$. Urinary excretion of thiamine accounts for a minor part of normal thiamine turnover: pyrimidine and thiazole degradation products of thiamine are also excreted in the urine and account for the major component of thiamine turnover [20]. Rather, low plasma thiamine concentration was linked to a profound increase in $\mathrm{Cl}_{\text {Thiamine }}$ and $\mathrm{FE}_{\text {Thiamine. The molecular mass of thiamine }}$ is $<500 \mathrm{Da}$ and hence it is filtered from plasma in renal glomeruli [10]. Increased $\mathrm{Cl}_{\text {Thiamine }}$ is probably due to decreased re-uptake of thiamine in renal proximal tubules. Thiamine clearance was dysfunctional in diabetic patients with normal GFR, as assessed by creatinine clearance. This study suggests renal mishandling of thiamine in diabetic patients is an early marker of renal dysfunction in diabetes and, linked to the locus of renal thiamine re-uptake, particularly relates to proximal tubule dysfunction.

Re-uptake of thiamine occurs in the proximal tubules by thiamine transporters THTR-1 and THTR-2 via a sodiumindependent, proton antiport mechanism with regulation by $\mathrm{Ca}^{2+} /$ calmodulin [21]. The expression of the genes encoding THTR-1 and THTR-2 (and also RFC-1) transporters are regulated via SP1 promoter elements [22-24]. SP1 signalling in the tubular epithelium is impaired in hyperglycaemia associated with diabetes by increased $O$-glycosylation of the SP1 via enhanced hexosamine pathway activity [25]. Re-uptake of thiamine by the tubular epithelium in experimental diabetes [26] and clinical diabetes (this work) may be impaired by hexosamine pathway-linked decreased expression of the genes encoding THTR-1 and THTR-2, inhibition of these thiamine transporters by dicarbonyl glycation [27] and acidification of the tubular lumen [28]. This deserves further investigation.

A weakness of the study was the finding of no strong link to a recognised clinical endpoint such as incipient nephropathy judged by microalbuminuria, although there was a weak negative correlation of erythrocyte TK activity
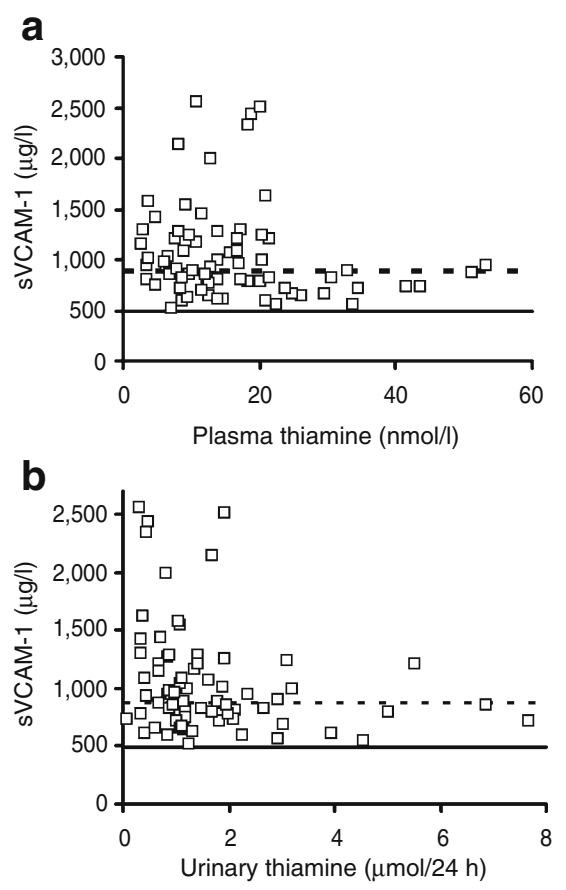

Fig. 3 Correlation of SVCAM-1 with plasma thiamine concentration (a) and urinary thiamine excretion (b). Solid horizontal line, reference mean of sVCAM-1 of normal volunteers; broken horizontal line, upper limit of sVCAM-1 of normal volunteers 
with urinary albumin excretion. It is becoming increasingly evident, however, that urinary albumin excretion may not be a reliable marker of early stage decline in renal function in diabetes [29]. Future studies would be probably better addressed to investigation of the link between changes in thiamine homeostasis and early decline in GFR assessed by cystatin $\mathrm{C}$ measurement [30].

Decreased plasma thiamine concentration has been reported in diabetic patients previously in studies with small patient numbers $[31,32]$ but $\mathrm{Cl}_{\text {Thiamine }}$ and $\mathrm{FE}_{\text {Thiamine, }}$ thiamine and TMP transporter content of erythrocyte membranes and plasma sVCAM-1 were not evaluated and hence links to these variables were not disclosed. Thiamine deficiency is conventionally assessed by measuring the percentage unsaturation of erythrocyte TK with TPP cofactor [12]. Herein we found, however, that plasma deficiency of thiamine in diabetes was masked in erythrocytes by increased levels of THTR-1 and RFC-1 transporter protein. As erythrocytes lack protein synthetic capability, increased protein levels of these transporters was produced by increased expression of the genes encoding THTR-1 and RFC-1 in the erythrocyte precursors, reticulocytes and erythroblasts. Indeed, increased levels of THTR-1 and RFC-1 transporter proteins were also found in MNLs in these diabetic patients (data not shown). Increased thiamine transporter gene expression and protein level is a response to thiamine deficiency $[21,33]$ and is consistent with the low plasma thiamine concentration found in diabetic patients herein. This explains why a low plasma thiamine concentration in clinical diabetes has hitherto gone unrecognised. This study indicates that the measurement of the 'thiamine effect' based on erythrocyte TK activities is an inadequate assessment of clinical thiamine status as it can be masked by changes in thiamine transporter protein levels.

Low plasma thiamine concentration in diabetes may be of limited significance if tissues can upregulate the gene expression and protein levels of thiamine transporters and maintain normal TK activity. Although this occurs in the normoglycaemic state [21,33], our recent studies of experimental diabetes indicated it does not occur in renal glomeruli in the diabetic state [26] where enhanced hexosamine signalling may block increased expression of the genes encoding THTR-1, THTR-2 and RFC-1 and their protein levels. In diabetic glomeruli, TK activity and level of TK protein was decreased $60 \%$ [26], and similar impairment of thiamine uptake and metabolism may occur in the diabetic retina and peripheral nerve [34, 35]. Indeed, RFC-1 has impaired gene expression and protein levels in the diabetic retina [35].

Decreased availability of thiamine in vascular cells in diabetes exacerbates metabolic dysfunction in hyperglycaemia. Increased plasma sVCAM-1 is a marker of endothelial dysfunction [36] and increased risk of atherosclerosis [37].
sVCAM-1 was increased in diabetic patients with normal renal function [38] and was linked to microvascular and macrovascular complications in diabetes [39-41], although the link to glycaemic control is less certain [39, 42, 43]. Low plasma thiamine concentration may be a confounding factor linked to increased sVCAM-1 in diabetes.

This study indicates that type 1 and type 2 diabetic patients in the UK exhibit low plasma thiamine concentration. The conventional indicator of thiamine sufficiency, erythrocyte TK activity, is masked in clinical diabetes by increased protein levels of thiamine and TMP transporters, THTR-1 and RFC-1. The deficiency of thiamine in clinical diabetes may increase the fragility of vascular cells to the adverse effects of hyperglycaemia and thereby increase the risk of developing microvascular complications. Correction of the low plasma thiamine concentration with thiamine supplements may decrease the risk of microvascular complications in diabetes.

Important areas for future study are: (1) confirmation of low plasma thiamine concentrations in diabetic populations of other countries independent of local dietary and culinary practice; (2) the evaluation of thiamine and thiamine derivatives to correct low plasma thiamine concentration in diabetes, reverse vascular dysfunction and prevent vascular complications; and (3) investigation of the mechanism of increased $\mathrm{Cl}_{\text {Thiamine }}$ in diabetes. These studies are either ongoing or in preparation.

Acknowledgements This study was funded by a project grant from Diabetes UK (RD/04/2812).

Duality of interest The authors declare that there is no duality of interest associated with this manuscript.

\section{References}

1. Donnelly R, Emslie-Smith AM, Gardner ID, Morris AD (2000) $\mathrm{ABC}$ of arterial and venous disease: vascular complications of diabetes. BMJ 320:1062-1066

2. American Diabetes Association (2007) Standards of medical care in diabetes-2007. Diabetes Care 30:S4-S41

3. Saydah SH, Fradkin J, Cowie CC (2004) Poor control of risk factors for vascular disease among adults with previously diagnosed diabetes. JAMA 291:335-342

4. Parving HH, Lewis JB, Ravid M, Remuzzi G, Hunsicker LG (2006) Prevalence and risk factors for microalbuminuria in a referred cohort of type II diabetic patients: a global perspective. Kidney Internat 69:2057-2063

5. The Diabetes Control and Complications Trial Research Group (1993) The effect of intensive treatment of diabetes on the development and progression of long-term complications in insulin-dependent diabetes mellitus. New Engl J Med 327:977-986

6. Stratton IM, Adler AI, Neil HAW et al (2002) Association of glycaemic with macrovascular and microvascular complications of type 2 diabetes (UKPDS 35): prospective observational study. BMJ 321:405-412 
7. Rogus JJ, Warram JH, Krolewski AS (2002) Genetic studies of late diabetic complications: the overlooked importance of diabetes duration before complication onset. Diabetes 51:1655-1662

8. Placha G, Poznik GD, Dunn J et al (2006) A genome-wide linkage scan for genes controlling variation in renal function estimated by serum cystatin $\mathrm{C}$ levels in extended families with type 2 diabetes. Diabetes 55:3358-3365

9. Costacou T, Chang Y, Ferrell RE, Orchard TJ (2006) Identifying genetic susceptibilities to diabetes-related complications among individuals at low risk of complications: an application of treestructured survival analysis. Am J Epidemiol 164:862-872

10. Thornalley PJ (2005) The potential role of thiamine (vitamin B1) in diabetic complications. Curr Diabetes Res 1:287-298

11. Babaei-Jadidi R, Karachalias N, Kupich C, Ahmed N, Thornalley PJ (2004) High dose thiamine therapy counters dyslipidaemia in streptozotocin-induced diabetic rats. Diabetologia 47:2235-2246

12. Brady JA, Rock CL, Horneffer MR (1995) Thiamin status, diuretic medications, and the management of congestive heart failure. J Am Diet Assoc 95:541-544

13. Sander S, Hahn A, Stein J, Rehner G (1991) Comparative studies on the high performance liquid chromatographic determination of thiamine and its phosphate esters with chloroethylamine as an internal standard using precolumn and postcolumn derivatization procedures. J Chromatogr 558:115-124

14. Dawson RMC, Elliott DC, Elliott WH, Jones KM (1989) Data for biochemical research, 3rd edn. Oxford University Press, Oxford

15. Cull CA, Manley SE, Stratton IM et al (1997) Approach to maintaining comparability of biochemical data during long-term clinical trials. Clin Chem 43:1913-1918

16. Dutta B, Huang W, Molero M et al (1999) Cloning of the human thiamine transporter, a member of the folate transporter family. J Biol Chem 274:31925-31929

17. Zhao R, Gao F, Goldman ID (2002) Reduced folate carrier transports thiamine monophosphate: an alternative route for thiamine delivery into mammalian cells. Am J Physiol Cell Physiol 282:C1512-C1517

18. Churchward M, Butt RH, Lang J, Hsu K, Coorssen J (2005) Enhanced detergent extraction for analysis of membrane proteomes by two-dimensional gel electrophoresis. Proteome Sci 3:5

19. Finglas PM (1993) Thiamin. Internat J Vitam Nutr Res 63:270274

20. Ziporin ZZ, Nunes WT, Powell RC, Waring PP, Sauberlich HE (1965) Thiamine requirement in the adult human as measured by urinary excretion of thiamine metabolites. J Nutr 85:297-304

21. Ashokkumar B, Vaziri ND, Said HM (2006) Thiamin uptake by the human-derived renal epithelial (HEK-293) cells: cellular and molecular mechanisms. Am J Physiol Renal Physiol 291:F796-F805

22. Reidling JC, Said HM (2003) In vitro and in vivo characterization of the minimal promoter region of the human thiamin transporter SLC19A2. Am J Physiol Cell Physiol 285:C633-C641

23. Nabokina SM, Said HM (2004) Characterization of the $5^{\prime}$ regulatory region of the human thiamin transporter SLC19A3: in vitro and in vivo studies. Am J Physiol Gastrointest Liver Physiol 287:G822-G829

24. Tolner B, Singh A, Esaki T, Roy K, Sirotnak FM (1999) Transcription of the mouse RFC-1 gene encoding a folate transporter. Multiplicity and properties of promoters with minimum requirements for their basal activity. Gene 231:163-172

25. Schleicher ED, Weigert C (2000) Role of the hexosamine biosynthetic pathway in diabetic nephropathy. Kidney Int 58:S13-S18

26. Babaei-Jadidi R, Karachalias N, Ahmed N, Battah S, Thornalley PJ (2003) Prevention of incipient diabetic nephropathy by high dose thiamine and Benfotiamine. Diabetes 52:2110-2120
27. Verri A, Laforenza U, Gastaldi G, Tosco M, Rindi G (2002) Molecular characteristics of small intestinal and renal brush border thiamin transporters in rats. Biochim Biophys Acta 1558:187-197

28. Nascimento-Gomes G, Zaladek Gil F, Mello-Aires M (1997) Alterations of the renal handling of $\mathrm{H}+$ in diabetic rats. Kidney Blood Press Res 20:251-257

29. Perkins BA, Ficociello LH, Ostrander BE et al (2007) Microalbuminuria and the risk for early progressive renal function decline in type 1 diabetes. J Am Soc Nephrol 18:1353-1361

30. MacIsaac RJ, Tsalamandris C, Thomas MC et al (2007) The accuracy of cystatin $\mathrm{C}$ and commonly used creatinine-based methods for detecting moderate and mild chronic kidney disease in diabetes. Diabetic Med 24:443-448

31. Saito N, Kimura M, Kuchiba A, Itokawa Y (1987) Blood thiamine levels in outpatients with diabetes mellitus. J Nutr Sci Vitaminol 33:421-430

32. Valerio G, Franzese A, Poggi V, Patrini C, Laforenza U, Tenore A (1999) Lipophilic thiamine treatment in longstanding insulindependent diabetes mellitus. Acta Diabetol 36:73-76

33. Laforenza U, Patrini C, Alvisi C, Faelli A, Licandro A, Rindi G (1997) Thiamine uptake in human intestinal biopsy specimens, including observations from a patient with acute thiamine deficiency. Am J Clin Nutr 66:320-326

34. Gorson KC, Ropper AH (2006) Additional causes for distal sensory polyneuropathy in diabetic patients. J Neurol Neurosurg Psychiatry 77:354-358

35. Naggar H, Ola MS, Moore P et al (2002) Downregulation of reduced-folate transporter by glucose in cultured RPE cells and in RPE of diabetic mice. Invest Ophthalmol Vis Sci 43:556-563

36. Stehouwer CDA, Gall MA, Twisk JWR, Knudsen E, Emeis JJ, Parving H-H (2002) Increased urinary albumin excretion, endothelial dysfunction, and chronic low-grade inflammation in type 2 diabetes. Diabetes 51:1157-1165

37. Jager A, van Hinsbergh VW, Kostense PJ et al (2000) Increased levels of soluble vascular cell adhesion molecule 1 are associated with risk of cardiovascular mortality in type 2 diabetes: the Hoorn study. Diabetes 49:485-491

38. Lim SC, Caballero AE, Smakowski P, LoGerfo FW, Horton ES, Veves A (1999) Soluble intercellular adhesion molecule, vascular cell adhesion molecule, and impaired microvascular reactivity are early markers of vasculopathy in type 2 diabetic individuals without microalbuminuria. Diabetes Care 22:1865-1870

39. Fasching P, Veitl M, Rohac M et al (1996) Elevated concentrations of circulating adhesion molecules and their association with microvascular complications in insulin-dependent diabetes mellitus. J Clin Endocrinol Metab 81:4313-4317

40. Koga M, Otsuki M, Kubo M, Hashimoto J, Kasayama S (1998) Relationship between circulating vascular cell adhesion molecule-1 and microvascular complications in type 2 diabetes mellitus. Diabet Med 15:661-667

41. Soedamah-Muthu SS, Chaturvedi N, Schalkwijk CG, Stehouwer CDA, Ebeling P, Fuller JH (2006) Soluble vascular cell adhesion molecule-1 and soluble E-selectin are associated with micro- and macrovascular complications in type 1 diabetic patients. J Diabetes Complications 20:188-195

42. Schaumberg DA, Glynn RJ, Jenkins AJ et al (2005) Effect of intensive glycemic control on levels of markers of inflammation in type 1 diabetes mellitus in the diabetes control and complications trial. Circulation 111:2446-2453

43. Matsumoto K, Nakamura H, Ueki Y, Tominga T, Miyake S (2001) Correction of hyperglycaemia reduces insulin resistance and serum soluble E-selectin levels in patients with type 2 diabetes mellitus. Diabet Med 18:224-228 